\title{
Fair Shale Gas Water Cost Distribution Using Nash Bargaining Game
}

\author{
Alba Carrero-Parreño ${ }^{a}$, Vivek Dua ${ }^{a}$, Lazaros G. Papageorgiou ${ }^{a \dagger}$ \\ ${ }^{a}$ Centre for Process Systems Engineering, Department of Chemical Engineering, UCL (University \\ College London), Torrington Place, London WC1E 7JE, UK
}

\begin{abstract}
In this work, we address the optimal water management strategies and fair cost distribution among various shale gas companies placed in the same play. A mixed integer non-linear programming (MINLP) formulation with the objective of maximizing the Nash product is presented including the analysis of different policies to determine the most appropriate transportation cost distribution. As a result of Nash product maximization and transfer cost designation formulation, the problem includes non-linearities in the objective function which hinders its resolution. Therefore, to solve the model effectively, we apply logarithmic operation and separable programming approach to reformulate the Nash product and Glover's linearization to reformulate the bilinear terms appearing in the transfer cost designation. Finally, the applicability of the proposed approach is illustrated in a case study comprising 4 companies. Then, an example comprising 10 shale gas companies is performed to analyse the behaviour of the proposed formulation considering a larger problem.
\end{abstract}

Keywords: Shale Gas, Water Management, Fair Planning, Game Theory, Nash Product

\section{Introduction}

Change in total primary energy demand will continue increasing over the coming 25 years (U.S. Energy Information Administration, 2019). Although renewable energy will undergo the major growth, natural gas consumption will rise by nearly $50 \%$ being shale gas the major contributor. For instance, in the U.S., it is expected that shale gas will account for around $75 \%$ of the total natural gas production by 2050 .

The extraction techniques applied (horizontal drilling and hydraulic fracturing) to release the gas trapped in the shale formation constitute the major drawback of this energy resource (Gao

\footnotetext{
${ }^{\dagger}$ Corresponding author. Email: l.papageorgiou@ucl.ac.uk (L.G. Papageorgiou)
} 
and You, 2017(b)). Large amount of water, around 7500-3800 $\mathrm{m}^{3}$ per well, is injected under high pressure to fracture the rock (United States Environmental Protection Agency (EPA), 2016; Rahm \& Riha, 2012 ). Then, part of the water, highly contaminated, is recovered.

Currently, the reuse of this wastewater to fracture other wells is essential to reduce the water footprint (Caballero et al., 2020). Many papers have been published optimizing shale gas water management strategies, minimizing the water consumption and total operational cost (Gao \& You, 2015; Lira-Barragán et al., 2016(a), 2016(b); Yang et al., 2014, 2015; Drouven et al., 2017; Carrero-Parreño et al., 2018; Guerra et al., 2019, Oke et al., 2020). However, to minimize the total water consumption, shale gas companies working in the same area need to agree on a water management strategy. Note that fracturing a well using the wastewater that comes from another well, usually placed nearby, means important saving for the company which is extracting the gas. This implies an inevitable competition among these companies to achieve the lowest water management cost and, consequently, the best sales price at the energy market. However, shale gas play can be contemplated as collaborative network where members can have better economic outcome working together than being isolated with only self-interest.

Game theory is a powerful area for studying strategic interaction among reasonable decision makers, which has been applied to a number of planning schemes in different applications (Stadler, 2009). The benefit of the players would not only depend on their own choices but also on the choices of the other players. The main concern arises on the obtaining a fair cost allocation where all members receive a reasonable or acceptable portion of costs. Mainly, there are two approaches to analyse the strategies of individual companies, called coalitional or cooperative game theory and non-cooperative game theory.

The first one is base on the work of von Neumann and Morgensterm (1944), which analyses the formation of various coalitions by the players of the game. Their approach, in which players are treated as a team with a common purpose, predicts the joint actions that groups take and the resulting collective pay-off. The most popular solution method to determine a set of possible cost or profit allocation is the core, especially in economic theory. As this method provides a set of solutions, one needs to decide is which solution is fair enough to be chosen. Drechsel and Kimms (2010) introduced some reformulations to obtain a fair element in the core. 
These concepts have been applied by Carrero-Parreño et al. (2019) to determine fair profit, cost and environmental allocation in the framework of shale gas water management. However, the solution provided is not fair enough for all the members. Additionally, the main challenge arises when the number of companies increase. This is because the number of coalitions rises exponentially with an increasing number of members and the analysis of each coalition should be made.

The second one is initiated by Nash $(1950,1951)$, which is based on the absence of coalitions and assumes that each participant acts independently. This approach analyses players' individual strategies and bargaining pay-off finding the Nash equilibrium. To obtain fair solutions, Nash suggested a concept called Nash bargaining solution (Nash product), in which the bargaining among players may result in cooperative actions. This concept assumes that the utility allocation depends on the utility expected if the negotiation fail and the feasible utility when companies work together. This method has been broadly applied in different areas of the process system field, such as fair profit (or cost) sharing between corporations and resources allocation problems (Gjerdrum et al., 2001, 2002; Yaiche et al., 2000; Zhang et al., 2013, 2017).

Regarding game theory in shale gas framework, apart from the above-mentioned work developed by Carrero-Parreño et al. (2019) where cooperative approach is used to distribute water-related costs, Gao and You (2017(a), 2019) applied a particular class of games called leader-follower Stackelberg game structure for the complete shale gas supply chain. Chen et al. (2020) developed a multi-level model with a set of leader-follower-interactive objectives with emphases of water consumption, economic performance, and pollutant discharge.

In this paper, we develop a mathematical formulation to fair cost distribution applying Nash bargaining principle for shale gas water management. We consider that all companies have the same bargaining power; however, the formulation includes the possibility of power allocation. Additionally, wastewater transportation cost assignation is added as new decision variable compared with the typical shale water management models. Specifically, several policies are analysed regarding this transportation cost assignation to provide different solutions to the decision makers.

Consequently to the Nash bargaining objective function and transfer cost designation, the 
problem is formulated as mixed-integer non-linear programming (MINLP) model first. Then, it is reformulated as a MILP by applying a logarithmic operation and a separable programming approach in the objective function and a Glover's linearization in the bilinear terms appearing in the tranfer cost allocation.

The rest of the paper is organized as follows. Section 2 details the problem statement and assumptions. Section 3 describes the Nash bargaining approach and the problem linearization. In section 4 , the proposed formulation is applied to a small example with 4 shale gas companies. Then, to analyse the behaviour of the formulation considering a higher number of companies, an example with 10 companies is performed. Finally, the conclusions are provided in Section 5.

\section{Problem description}

A shale gas play is comprised by several wellpads, and, in turn, one wellpad is formed by several wells. In this paper, we contemplate that each wellpad is owned by one company as shown in Figure 1 (a) and, at the same time, one company can own one or more wellpads. These companies placed in the same area can interact with each other to reduce water management costs; however, they will be willing to do it if a fair cost is allocated to each company relative to the cost allocated to the others.

To address water management decisions and interaction between companies, the shale gas water management superstructure displayed is Figure $\mathbf{1}$ (b) is considered in this work. To satisfy the water requirements to fracture each well, companies can withdraw water from a freshwater source, or use the wastewater that comes out after fracturing operations that belong to any company. If the wastewater is not used as a fracturing fluid, companies have the possibility to send it to a disposal site, a centralized water treatment plant or to treat it onsite. Moreover, they can place an onsite treatment on their own well pad or use the treatment that belongs to another company. If one company is using the treatment that belongs to another company, this company will pay the latter extra costs to the company that has installed the portable treatment. In case of wastewater recycling, the wastewater transportation aiming its reuse to fracture other wells can be paid by the issuer, receiver or share between them depending on the 
policy selected. Hence, companies can interact with each other recycling water among different wellpads or sharing onsite water treatment technologies.

The problem can be stated as follows: Given (a) a set of wellpads, companies, disposal wells, CWT plants and freshwater sources, (b) distance between different locations, (c) water demand per well, (d) capacity of freshwater and production tanks, and (e) cost coefficients of storage, transportation, treatment and disposal, determine (a) when and how much water each company recycles inside its wellpads, sends to another wellpad, treats or sends to a Class II disposal well, (b) quantity of water withdrawal from a specific natural source, (c) optimal location of the onsite treatments, (d) total number of freshwater and fracturing tanks leased, (e) payer of wastewater transportation among companies, (f) water management cost allocated to each company, in order to (a) find the companies' strategies which result in an optimal fair cost distribution maximizing the Nash product and (b) satisfy the water demand.

As only water management strategies are analysed in this study, we assume that each company fix its fracturing schedule in advance that maximizes its revenue in advance and the water treatment, including pretreatment and desalination, provides the adequate water quality for the next operations. Moreover, we consider a fixed time horizon (discretised weekly as time intervals) and water transportation via trucks.

\section{Nash bargaining approach}

In this section, the Nash bargaining formulation and the breakdown cost are detailed. Specifically, we describe the non-linear objective function and the approach used to reformulate the resulting Mixed Integer Nonlinear Programming (MINLP) model into Mixed Integer Linear Programming (MILP). The rest of the constraint that defines the water management planning model and nomenclature used can be found in Appendix A. Note that the water management planning model is a simplified version based on previous work presented by Carrero-Parreño et al. (2018).

\subsection{Non-linear objective function}

The objective is to minimize the water management operational cost while distributing the cost fairly among each company. An approach of optimizing the shale gas water management is to minimize the sum of the total cost per company. However, this solution could lead to an unfair 


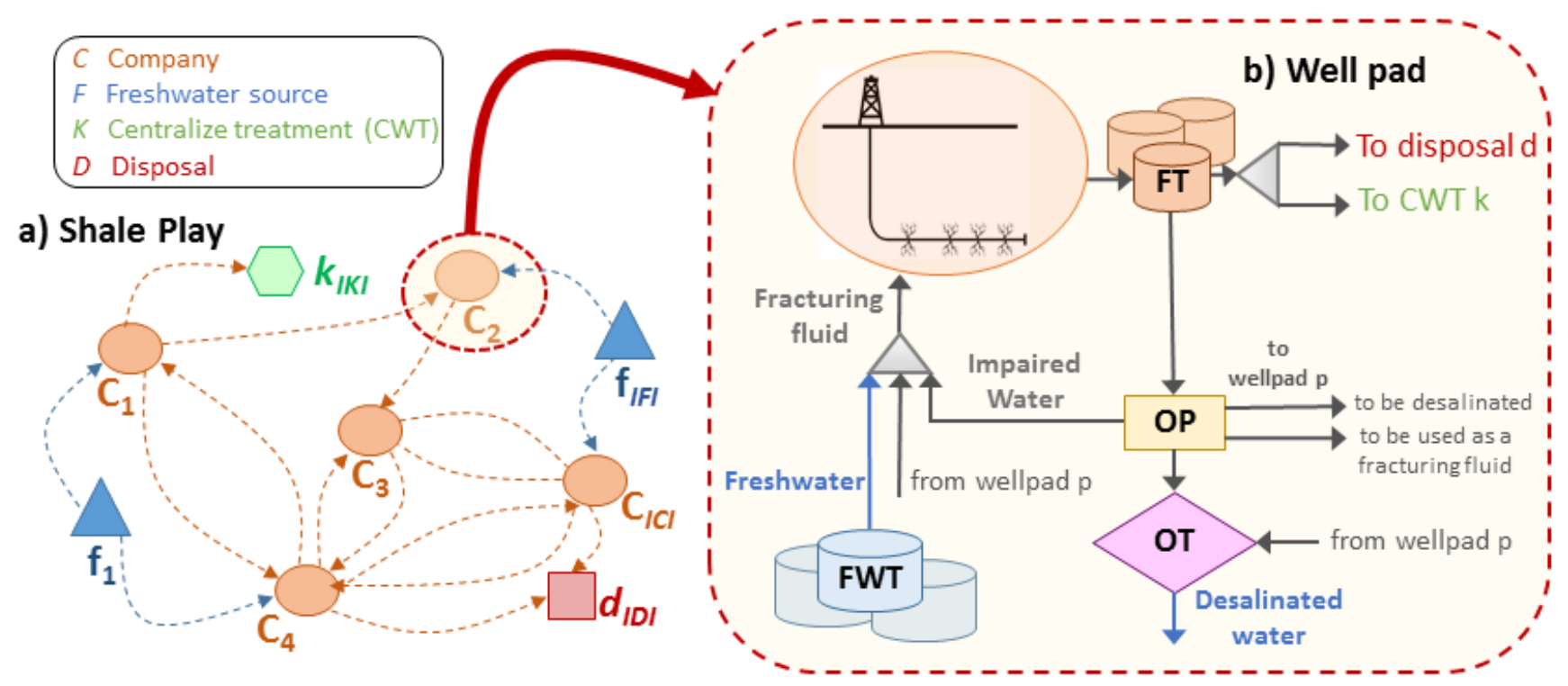

FWT: Freshwater tank / FT: Fracturing tank /OP: Onsite pre-treatment /OT: Onsite treatment

Figure 1: a) Representative shale gas extraction play belonging to different companies; b) Wellpad water management strategies.

distribution among the members being unattractive to some companies.

For that reason, we apply game theory Nash Bargaining solution to achieve a fair cost distribution among them. The objective function maximizes the product of the deviations of the given maximum cost of each company, i.e. each company yields minimum cost while maximizing the following objective function.

$$
\Phi=\max \prod_{i}\left(T C_{i}^{U P}-t c_{i}\right)^{\alpha_{i}}
$$

$T C_{i}^{U P}$ is the operational cost of company $i$ working without interacting with the others and $t c_{i}$ is the water management cost for company i when companies are interacting. The previous objective function takes into account the bargaining powers $\left(\alpha_{i}\right)$ of the members. If all companies have the same power, $\alpha_{i}$ can be removed from Eq.(1) and the power will be distributed equally among them.

\subsection{Breakdown costs}

For each company $i$, the total cost consists of the following disaggregated costs: storage $\left(c_{i}^{s}\right)$, freshwater withdrawal $\left(c_{i}^{f}\right)$, offsite treatment $\left(c_{i}^{c}\right)$, disposal $\left(c_{i}^{d}\right)$, pretreatment $\left(c_{i}^{p}\right)$, onsite 
treatment $\left(c_{i}^{o}\right)$, transportation $\left(c_{i}^{t}\right)$ and inter-company transportation cost $\left(c_{i}^{t r}\right)$.

$$
t c_{i}=c_{i}^{s}+c_{i}^{f}+c_{i}^{c}+c_{i}^{d}+c_{i}^{p}+c_{i}^{o}+c_{i}^{t}+c_{i}^{t r} \quad \forall i \in I
$$

The storage cost includes the leasing cost $\left(\alpha^{s}\right)$ per tank installed and the mobilizing, demobilizing and cleaning cost $\left(\beta^{s}\right)$.

$$
c_{i}^{s}=\sum_{t \in T} \sum_{p \in G_{i p}} \sum_{s \in S}\left[\alpha^{s} \cdot n_{t p s}+\beta^{s} \cdot n_{t p s}^{i n}\right] \quad \forall i \in I
$$

$n_{t p s}$ refers to the tank type $s$ placed in wellpad $p$ in time period $t$ and $n_{t p s}^{i n}$ are the tank type $s$ intalled in wellpad $p$ in time period $t$.

Freshwater withdrawal, centralized water treatment and disposal cost depend on the water withdrawal cost from diverse sources $f\left(\alpha_{f}^{f r e s h}\right)$, the cost imposed by the CWT plant $k\left(\alpha_{k}^{\text {off }}\right)$ and the disposal cost $d\left(\alpha_{d}^{d i s}\right)$.

$$
c_{i}^{f}+c_{i}^{c}+c_{i}^{d}=\sum_{t \in T} \sum_{p \in G_{i p}}\left[\sum_{f \in F} \alpha_{f}^{f r e s h} \cdot f_{t p f}^{s}+\sum_{k \in K} \alpha_{k}^{o f f} \cdot f_{t p k}^{c}+\sum_{d \in D} \alpha_{d}^{d i s} \cdot f_{t p d}^{d}\right] \quad \forall i \in I
$$

$f_{t p f}^{s}, f_{t p k}^{c}$ and $f_{t p d}^{d}$ are the flowrate withdrawal from natural source and the flowrate sent to a CWT plant or disposal site, respectively.

Pretreatment cost varies depending on the final destination of the water (Carrero-Parreño et al., 2017). If the water is used as a fracturing fluid, the pretreatment is less restrictive than if it is sent to a desalination treatment since the presence of scaling compounds can damage the equipment. Note that, before sending the water to another location the wellpad has to deal with the water pretreatment.

$$
c_{i}^{p}=\sum_{t \in T} \sum_{p \in G_{i p}}\left[\alpha^{p r e 1} \cdot\left(f_{t p}^{i}+\sum_{p^{\prime} \in P} g_{t p p^{\prime}}^{i}\right)+\alpha^{p r e 2} \cdot\left(f_{t p}^{t}+\sum_{p^{\prime} \in P} g_{t p p^{\prime}}^{t}\right)\right] \quad \forall i \in I
$$

$f_{t p}^{i}$ is the water used as a fracturing fluid in the same wellpad, $g_{t p p^{\prime}}^{i}$ is the wastewater used as a fracturing fluid in another wellpad, $f_{t p}^{t}$ refers the water sent to an onsite treatment in the same wellpad, $g_{t p p^{\prime}}^{t}$ is the wastewater sent to a onsite treatment placed in another wellpad, $\alpha^{p r e 1}$ is 
the cost aiming its recycling and $\alpha^{\text {pre2 }}$ aiming its treatment.

Onsite desalination cost includes the desalination cost $\left(\alpha_{p}^{o n}\right)$ from treating the water that comes from the same company and the installation cost $\left(\beta_{p}^{o n}\right)$. Additionally, if the water is sent to an onsite treatment that belongs to another company $i$, the company $i$ has additional charge $\xi$ compared if the portable treatment is installed in its own wellpad. Hence, that increment $\xi$ is discounted for the company that has installed the onsite treatment.

$c_{i}^{o}=\sum_{t \in T} \sum_{p \in G_{i p}}\left[\alpha_{p}^{o n} \cdot f_{t p}^{t}+\beta_{p}^{o n} \cdot y_{p}^{o n}+\sum_{p^{\prime} \in G_{i p^{\prime}}} \alpha_{p^{\prime}}^{o n} \cdot g_{t p p^{\prime}}^{t}+\sum_{p^{\prime} \in G_{i^{\prime} p^{\prime}}} \alpha_{p^{\prime}}^{o n} \cdot(1+\xi) \cdot g_{t p p^{\prime}}^{t}-\sum_{p^{\prime} \in G_{i^{\prime} p^{\prime}}} \alpha_{p}^{o n} \cdot \xi \cdot g_{t p^{\prime} p}^{t}\right] \quad \forall i \in I$

$y_{p}^{o n}$ is a binary variable that indicates where the onsite treatment must be installed.

Transportation cost via trucks includes the transportation of wastewater from wellpad $p$ to $p$ ' aiming to be desalinated in an onsite treatment and aiming to be used as a fracturing fluid in a wellpad that belongs to the same company; from wellpad $p$ to CWT plant $k$ or, disposal site $d$; and from natural source $f$ to wellpad $p$.

$$
\begin{aligned}
c_{i}^{t}=\sum_{t \in T} \sum_{p \in G_{i p}} \alpha^{t r u c k} \cdot\left[D W_{p p^{\prime}} \cdot\left[\sum_{p^{\prime} \in P} g_{t p p^{\prime}}^{t}+\sum_{p^{\prime} \in G_{i p^{\prime}}} g_{t p p^{\prime}}^{i}\right]\right. & +\sum_{k \in K} D O_{p k} \cdot f_{t p k}^{c} \\
& \left.+D D_{p d} \cdot f_{t p d}^{d}+\sum_{f \in F} D S_{p f} \cdot f_{t p f}^{s}\right] \quad \forall i \in I
\end{aligned}
$$

$D W_{p p^{\prime}}, D O_{p k}, D D_{p d}$ and $D S_{p f}$ refer to the distances between different locations.

Wastewater transportation cost from company $i$ to company $i$ ' is calculated as follows:

$$
c_{i i^{\prime}}^{i n t}=\alpha^{\text {truck }} \cdot \sum_{t \in T} \sum_{p \in G_{i p}} \sum_{p^{\prime} \in G_{i^{\prime} p^{\prime}}} g_{t p p^{\prime}}^{i} \cdot D W_{p p^{\prime}} \quad \forall i i^{\prime} \in I
$$

The question that arises is: Who pays wastewater transportation cost from company $i$ to company $i$ '? Should it be paid by the issuer, receiver or should be shared between them? This decision depends on the agreement made among the companies. Throughout this paper, we distinguish between three different policies depending on the answer of the previous question. In policy 1 the decision of transportation cost assignation is determined by the model. Therefore, in our mathematical formulation, we introduce a decision variable $\gamma_{i i^{\prime}}^{t r}$ to determine the portion 
of the cost assigned to each company.

$$
\begin{gathered}
c_{i}^{t r}=\sum_{i^{\prime} \in I} c_{i i^{\prime}}^{i n t} \cdot \gamma_{i i^{\prime}}^{t r}+c_{i^{\prime} i}^{i n t} \cdot\left(1-\gamma_{i^{\prime} i}^{t r}\right) \quad \forall i \in I \\
0 \leq \gamma_{i i^{\prime}}^{t r} \leq 1 \quad \forall i i^{\prime} \in I
\end{gathered}
$$

If $\gamma_{i i^{\prime}}^{t r}$ is equal to 1 means that company $i$ pays the transportation cost. However, this cost can be distributed between company $i$ and $i$ ' in case of $\gamma_{i^{\prime} i}^{t r}$ takes a value different to 0 or 1 . Let us illustrate the behaviour of these equations with a small example of two companies where the transportation cost from company 1 to company 2 is equal to 10 and from company 2 to company 1 equal to 8 . The transportation cost from 1 to 2 is paid for company 1 ; therefore, $\gamma_{12}^{t r}=1$. From company 2 to 1 , the cost being shared between them is $\gamma_{21}^{t r}=0.6$. Thus, the wastewater transportation cost for company 1 is $c_{1}^{t r}=10 \cdot 1+8 \cdot(1-0.6)=13.2$ and for company 2 equal to $c_{2}^{\text {tr }}=8 \cdot 0.6+10 \cdot(1-1)=4.8$.

In policy 2, company $i$ pays the transportation cost to send wastewater to company $i$ '. In this case, the model is simplified because $\gamma_{i i^{\prime}}^{t r}$ is fixed to 1 ; therefore, the bilinear term $c_{i i^{\prime}}^{i n t} \cdot \gamma_{i i^{\prime}}^{t r}$ which includes difficulties in the resolution disappears. The same applies to policy 3 where the receiver pays for transportation (company $i$ ' pays the transportation cost to receive the water that comes from company $i$ ). Finally, policy 4 enforces to assign the same cost portion between companies sharing wastewater by adding the following equality: $\gamma_{i i^{\prime}}^{t r}=\gamma_{i^{\prime} i}^{t r}$.

\subsection{Objective function linearization}

The model introduces non-linearities in the objective function (Eq.(1)) and in the calculation of wastewater transportation cost between companies considering policy 1 (Eq.(9)) which makes the problem intractable with a high number of wellpads and companies. These non-linear equations can be linearized using the following techniques.

Logarithmic operation and separable programming approach are used to linearize the non-linear objective function. In the separable programming approach a continuous convex function is approximated in intervals as a piecewise linear function using $q$ grid points. Eq.(1) is replaced 
by the following equations:

$$
\begin{gathered}
\Phi=\max \sum_{i \in I} \sum_{q \in Q} \lambda_{i q} \cdot \alpha_{i} \cdot \ln \left(T C_{i}^{U P}-T \hat{C}_{i q}\right) \\
t c_{i}=\sum_{q \in Q} T \hat{C}_{i q} \cdot \lambda_{i q} \quad \forall i \in I \\
\sum_{q \in Q} \lambda_{i q}=1 \quad \forall i \in I \\
\lambda_{i q} \geq 0 \quad \forall i \in I, q \in Q
\end{gathered}
$$

where $\lambda_{i q}$ is a SOS2 variable and $T \hat{C}_{i q}$ is the cost of member $i$ at grid point $q$. A detailed description of separable programming approach can be found in Gjerdrum et al.(2001).

The bilinear non-linear term displayed in Eq.(9) is reformulated using piecewise function. To do that, the variable that assigns the portion paid of wastewater transportation between two companies is discretized in $j$ values $\left(\hat{\gamma}_{j}^{\text {tran }}\right)$. The binary variable $x_{i i^{\prime} j}$ reflects the selection of the parameter $\hat{\gamma}_{j}^{\text {tran }}$. Then, the bilinear term formed by the multiplication of two continuous variables has been converted to a bilinear term composed by a continuous and binary variable. This non-linearity can be reformulated using Glover's linearization where the bilinear term is replaced by a new continuous variable $z_{i i^{\prime} j}$ and enforces Eq.(15) by adding four linear inequalities Eq.(16) - Eq.(19). $C^{L O}$ and $C^{U P}$ are the lower and upper bound of inter-company cost.

$$
\begin{gathered}
z_{i i^{\prime} j}=c_{i i^{\prime}}^{i n t} \cdot x_{i i^{\prime} j} \quad \forall j \in J, i i^{\prime} \in I, i \neq i^{\prime} \\
z_{i i^{\prime} j} \geq C^{L O} \cdot x_{i i^{\prime} j} \quad \forall j \in J, i i^{\prime} \in I, i \neq i^{\prime} \\
z_{i i^{\prime} j} \geq C^{U P} \cdot x_{i i^{\prime} j}+c_{i i^{\prime}}^{i n t}-C^{U P} \quad \forall j \in J, i i^{\prime} \in I, i \neq i^{\prime} \\
z_{i i^{\prime} j} \leq C^{U P} \cdot x_{i i^{\prime} j} \quad \forall j \in J, i i^{\prime} \in I, i \neq i^{\prime}
\end{gathered}
$$




$$
\begin{gathered}
z_{i i^{\prime} j} \leq C^{L O} \cdot x_{i i^{\prime} j}+c_{i i^{\prime}}^{i n t}-C^{L O} \quad \forall j \in J, i i^{\prime} \in I, i \neq i^{\prime} \\
\sum_{j \in J} x_{i i^{\prime} j}=1 \quad \forall i i^{\prime} \in I, i \neq i^{\prime}
\end{gathered}
$$

Finally, using this new variable $z_{i i^{\prime} j}$, Eq.(9) is reformulated as follows:

$$
c_{i}^{t r}=\sum_{\substack{i^{\prime} \in I \\ i \neq i^{\prime}}}\left[\sum_{j \in J} \hat{\gamma}_{j}^{t r} \cdot z_{i i^{\prime} j}+c_{i^{\prime} i}^{i n t}-\sum_{j \in J} \hat{\gamma}_{j}^{t r} \cdot z_{i^{\prime} i j}\right] \quad \forall i \in I
$$

\section{Ilustrative Examples}

First, a small numerical example composed of 30 wells distributed among 4 wellpads (each wellpad is owned for one company) is computed to analyse the performance of the proposed approach. Then, a higher example composed of 10 shale gas companies where each company owns 2-4 wellpads is solved. A total of 150 wells distributed into 30 wellpads are considered. Both examples are implemented in GAMS 25.1.3 (Rosenthal, 2016) and solved using a computer with 3GHz Intel Zeon Processor and 32 GB RAM running on Windows 10.

The upper bound costs $\left(T C_{i}^{U P}\right)$ are determined by considering only the water management strategies of each company minimizing the total water management cost $(\mathbf{E q}(2))$ subject to $\mathbf{E q ( 3 )}-\mathbf{E q ( 1 0 )}$ and $\mathbf{E q ( A . 1 ) ~ - ~ E q ( A . 1 1 ) . ~ T h a t ~ i s ~ t h e ~ m o d e l ~ i s ~ s o l v e d ~ f o r ~ e a c h ~ o f ~ t h e ~}$ previously defined companies, i.e. in case of four-shale gas companies example the model is solved four times. Then, knowing the upper bounds, both the MINLP and MILP formulation are solved. For the MINLP formulation, we maximize $\mathbf{E q ( 1 ) ~ s u b j e c t ~ t o ~} \mathbf{E q ( 2 )}-\mathbf{E q}(\mathbf{1 0})$ and $\mathbf{E q ( A . 1 ) ~ - ~ E q ( A . 1 1 ) . ~ I n ~ c a s e ~ o f ~ M I L P ~ f o r m u l a t i o n , ~} \mathbf{E q ( 1 1 ) ~ i s ~ m a x i m i z e d ~ s u b j e c t ~ t o ~} \mathbf{E q ( 1 2 )}$ - $\operatorname{Eq}(20), \operatorname{Eq}(2)-\operatorname{Eq}(8)$ and $\operatorname{Eq}(A .1)-\operatorname{Eq}(A .11)$. 


\subsection{A Four-Shale Gas Companies Example}

The four-shale gas companies example includes one interruptible water source, one disposal well and one centralized water treatment plant. To analyse which transportation policy brings the better outcome, the wastewater transportation cost between companies is calculated considering the four policies described before. Additionally, the problem is solved without considering the fairness criteria, namely $\sum_{i \in I} t c_{i}$ is minimized subject to $\mathbf{E q ( 2 )}-\mathbf{E q ( 1 0 )}$ and $\mathbf{E q ( A . 1 ) ~ - ~}$ $\operatorname{Eq}(\mathrm{A} .11)$

First, for policy 1, the model is solved using both the MINLP and MILP formulation. Table 1 shows the computational statistics, where the number of continuous and binary variables, equations, the solver used, the gap, the solution time and the objective function obtained is presented. The MINLP model is solved using global (Baron)(Kılınç and Sahinidis, 2019) and local solver (Dicopt)(Duran and Grossmann, 1986). The local solver Dicopt provides a solution in a CPU time of 20s; but, the solution reported is lower than the one reported using Baron with $6 \%$ optimality gap in 3600s. The solution time decreases significantly using the MILP formulation compared with the MINLP formulation. Moreover, the same objective function is achieved when 100 grids points are considered for the discretisation of the individual total cost and, small differences are found using 20 and 10 grid points. Note that in the MILP problem, the objective function displayed in brackets in Table $\mathbf{1}$ is a post-processing objective function, i.e. Eq.(1) is calculated using the results obtained from the MILP formulation.

The previous results highlight the efficiency of the proposed MILP formulation to maximizes Nash product considering policy 1. Following a comparison of the solution obtained applying policy 1, 2, 3 and 4 and without considering the fairness criteria is made.

\section{Inter-companies transportation cost policies analysis}

Table 2 displays results of the Nash product (Eq.(1)), lineal Nash product (Eq.(11)) and the sum of the water management cost of each company $\left(\sum_{i \in I} t c_{i}\right)$ obtained for each policy. Note that the values shown in column three of Table $\mathbf{2}$ are post-processed values since for policy 1, 2, 3 and 4 we maximize the Nash product (Eq.(1)) and the lineal Nash product (Eq.(11)). However, for policy 1 without considering the fairness criteria, we minimize the 
Table 1: Computational performance for the Four-Shale Companies Example

\begin{tabular}{|c|c|c|c|c|c|c|c|}
\hline \multirow[t]{3}{*}{ Type } & $\begin{array}{l}\text { \# of } \\
\text { continuous }\end{array}$ & $\begin{array}{l}\text { \# of } \\
\text { binary }\end{array}$ & $\begin{array}{l}\# \text { of } \\
\text { equations }\end{array}$ & Solver & $\begin{array}{l}\text { Gap } \\
(\%)\end{array}$ & $\begin{array}{l}\text { Solution } \\
\text { time }\end{array}$ & $\begin{array}{l}\text { Objective } \\
\text { function }\end{array}$ \\
\hline & variables & variables & & & & $(\mathrm{s})$ & \\
\hline & & & & Baron & 6 & 3600 & 9.793 \\
\hline MINLP & 24,409 & 2,500 & 17,109 & Dicopt & 0 & 20 & 9.499 \\
\hline \multirow{2}{*}{$\operatorname{MILP}(\mathrm{q}=5)^{*}$} & \multirow{2}{*}{24,677} & \multirow{2}{*}{2,632} & \multirow{2}{*}{17,657} & Cplex & 0 & 50 & $2.2543\left(9.707^{* *}\right)$ \\
\hline & & & & Gurobi & 0 & 12 & $2.2543\left(9.707^{* *}\right)$ \\
\hline \multirow{2}{*}{$\operatorname{MILP}(q=10)^{*}$} & \multirow{2}{*}{24,697} & \multirow{2}{*}{2,632} & \multirow{2}{*}{17,657} & Cplex & 0 & 42 & $2.2723\left(9.773^{* *}\right)$ \\
\hline & & & & Gurobi & 0 & 12 & $2.2723\left(9.773^{* *}\right)$ \\
\hline \multirow{2}{*}{$\operatorname{MILP}(q=20)^{*}$} & \multirow{2}{*}{24,727} & \multirow{2}{*}{2,632} & \multirow{2}{*}{17,657} & Cplex & 0 & 27 & $2.2775\left(9.784^{* *}\right)$ \\
\hline & & & & Gurobi & 0 & 13 & $2.2775\left(9.784^{* *}\right)$ \\
\hline \multirow{2}{*}{$\operatorname{MILP}(\mathrm{q}=100)^{*}$} & \multirow{2}{*}{25,057} & \multirow{2}{*}{2,632} & \multirow{2}{*}{17,657} & Cplex & 0 & 76 & $2.2815\left(9.792^{* *}\right)$ \\
\hline & & & & Gurobi & 0 & 13 & $2.2815\left(9.792^{* *}\right)$ \\
\hline
\end{tabular}

sum of the water management cost; hence, the results displayed for Eq.(1) and Eq.(11) are post-processing values. The highest Nash product is obtained using policy 1, which allows flexibility to assign wastewater transportation to the receiver or the issuer company. However, if the decision makers agree that companies interacting have to pay the same cost portion (policy 4), no significant differences are observed in the objective function.

There is a trade-off between obtaining the fairness saving ratio (defined as company cost working joinly compared to the upper cost) among companies and lowest companies joint cost. As can be seen in Figure 2, policy 1 is the most appropriate choice if the target of the companies agreement is to work jointly obtaining the fairest cost distribution among them. If companies interest is to minimize companies joint cost, no fairness criteria objective function has to be chosen. Note that choosing this option, savings for company 1 is only $13 \%$ compared with the upper bound (see Figure 2) being the Nash product significantly lower compared with the other cases. On the other hand, it is clear that policy 2 does not bring any benefit compare with policy 1 where the Nash product is lower and the total joint cost is higher. Instead, using 
Table 2: Four-Shale Companies Example: Comparison of Nash product, lineal Nash product and sum of the water management cost for each company obtained with each policy.

\begin{tabular}{cccc}
\hline Policy & Eq.(1) & Eq.(11) & $\sum_{i \in I} t c_{i}$ \\
\hline 1 & $9.79^{* *}$ & $2.28\left(9.79^{* * *}\right)$ & 9843 \\
2 & $9.11^{* *}$ & $2.21\left(9.12^{* * *}\right)$ & 9897 \\
3 & $9.47^{* *}$ & $2.25\left(9.51^{* * *}\right)$ & 9816 \\
4 & $9.60^{* *}$ & $2.27\left(9.65^{* * *}\right)$ & 9879 \\
$1 *$ & 6.48 & 0.69 \\
*Objective function without fairness criteria. \\
**Optimal solution obtained using the solver Baron and \\
solution time limit 3600s. \\
***MILP Post-processing objective function calculated \\
using Eq.(1).
\end{tabular}

policy 3 the Nash product is slightly lower, but the total joint cost decreases by $\$ 27 \mathrm{k}$. Figure 3 displays the water management company cost applying the before-mentioned policies. Note that the solution obtained using the MINLP and MILP formulation is displayed for policy 1. As can be seen, there are also minimum differences in water management cost between both formulations investigated.

\section{Water management strategy analysis}

Water management differences among the different policies can be shown in Table $\mathbf{3}$ where the total water withdrawal, total water recycled and onsite treatment ubication is displayed.

Figure 4 shows the disaggregated company cost distribution of the upper cost and those obtained maximizing the Nash product using policy 1 and without considering the fairness criteria. High savings are observed in the treatment of wastewater and transportation comparing the upper cost with the solution obtained with and without fairness criteria. When companies are not working as a cooperative network, they cannot reuse as much as wastewater for fracturing operations. Consequently, they have to withdraw more natural water increasing the transportation costs. The wastewater has to be managed by treating it or sending it to a disposal site, which increase the costs significantly. The optimal strategy maximizing Nash 


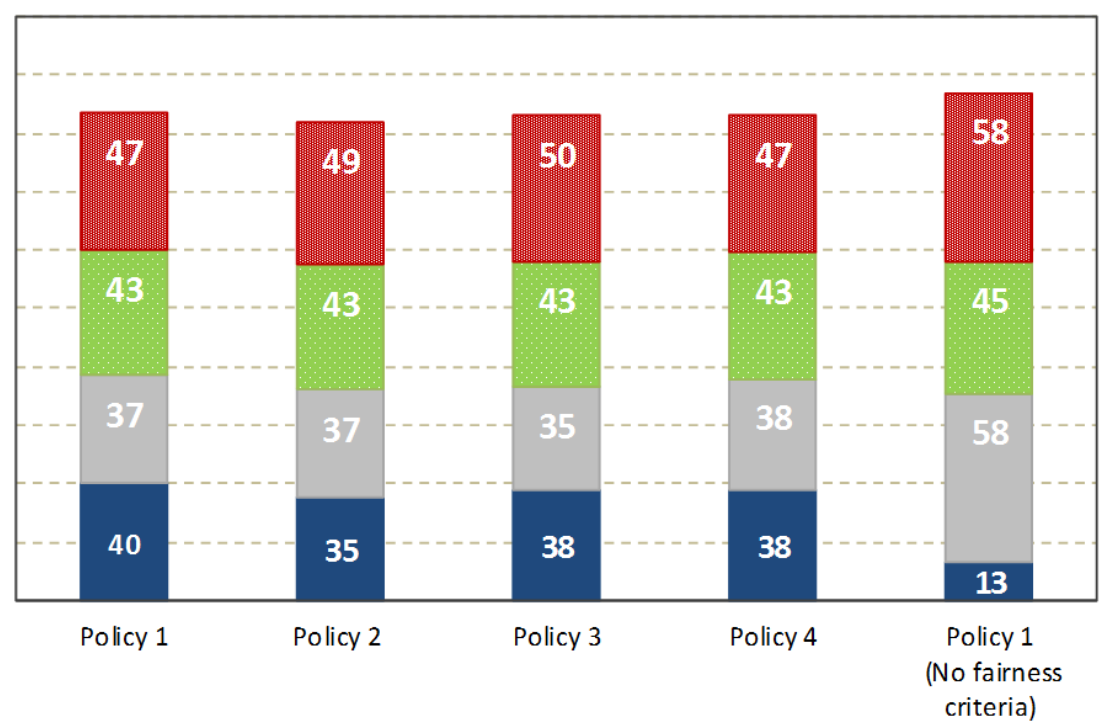

- Company $1 \square$ Company 2 Company 3 - Company 4

Figure 2: Four-Shale Companies Example: Saving ratio (defined company cost working jointly compared to the upper cost) obtained with each policy for each company

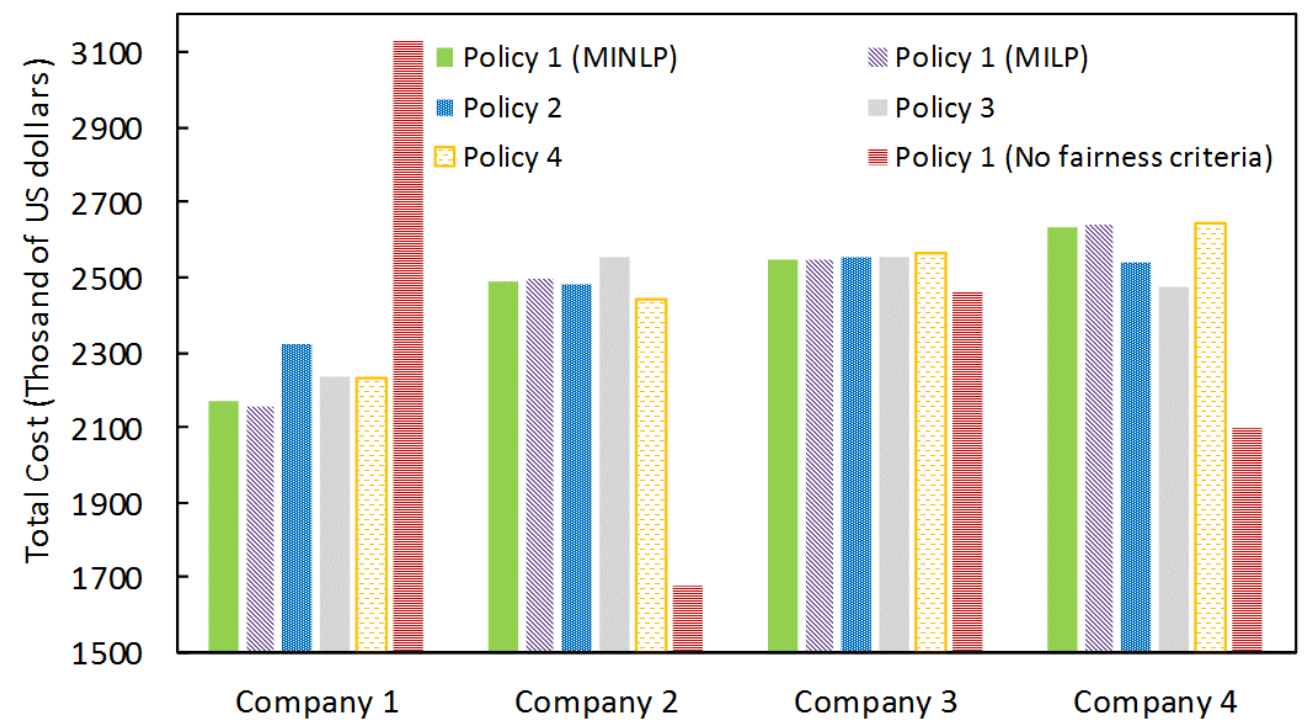

Figure 3: Four-Shale Companies Example: Optimal fair cost selected by different policies for each company c. 


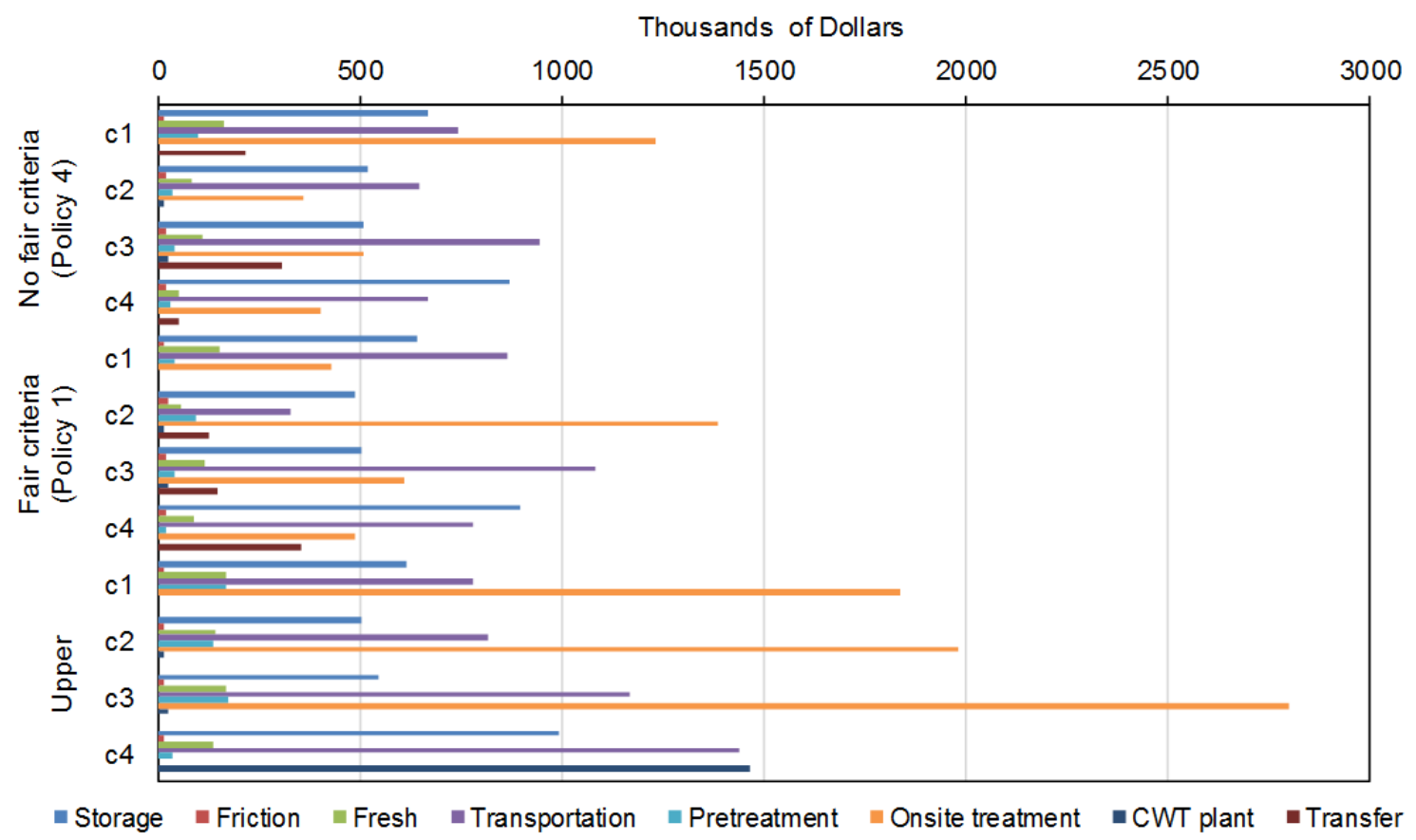

Figure 4: Four-Shale Companies Example: Breakdown cost per company of the upper cost and the ones obtained with policy 1 and 4 .

product using policy 1 reveals to install an onsite treatment in wellpad 2, which belongs to company 2. For that reason, onsite treatment cost for company 2 is significantly higher than for the other companies. However, this company has lower freshwater withdrawal and storage costs. Note that without considering the fairness criteria, onsite treatment is installed in company 1 which has the highest treatment cost.

Finally, the wastewater transportation cost assignation using policy 1 is detailed as follows.

Table 4 (a) shows the wastewater transportation cost for sending wastewater from company

Table 3: Water management solution per policy: total water recycled, total water withdrawal and onsite treatment ubication

Policy $1 \quad$ Policy 2 Policy 3 Policy 4 No fairness cirteria

$\begin{array}{lrrrrr}\text { Total water withdrawal }\left(m^{3}\right) & 2458 & 2440 & 2465 & 2245 & 2390 \\ \text { Total water recycled }\left(m^{3}\right) & 779356 & 774616 & 782215 & 780563 & 807955\end{array}$

Onsite treatment Ubication $\quad$ wellpad 2 wellpad 2 wellpad 2 wellpad 2 wellpad 1 
$i$ to company $i$. The mathematical model assigns if the transportation cost has to be shared between each company, or it has to be paid by the issuer or the receiver company. Table 4 (b) displays the cost assignation for each shipment. For example, the transportation cost from company 1 to companies 2, 3 and 4 is paid by these receiving companies. Therefore, variable $\gamma_{i 1 i 2}^{t r}$ equal to zero means that the company that owns wellpad i2 pays for the water transportation. On the contrary, variable $\gamma_{i 4 i 1}^{\text {tran }}$ equal to 1 means that company 4 pays for the wastewater transportation to company 1 . Note that the formulation developed allows to obtain shared transportation costs, that means that $\gamma_{i i^{\prime}}^{t r}$ can take any value from 0 to 1.

Table 4: Four-Shale Companies Example: (a) Transportation cost to transfer wastewater between companies $\left(C_{i i^{\prime}}^{i}\right)$; (b) Cost assignation to transport wastewater from company $i$ to $i$, $\left(\gamma_{i i^{\prime}}^{t r}\right)$ via MILP formulation.

(a)

\begin{tabular}{ccccc}
\hline company & i1 & i2 & i3 & i4 \\
\hline i1 & - & 127 & 8 & 76 \\
i2 & - & - & 141 & 7 \\
i3 & - & - & - & 154 \\
i4 & 48 & 48 & 5 & - \\
\hline
\end{tabular}

(b)

\begin{tabular}{ccccc}
\hline company & i1 & i2 & i3 & i4 \\
\hline i1 & - & 0 & 0 & 0 \\
i2 & - & - & 0 & 0 \\
i3 & - & - & - & 0 \\
i4 & 1 & 1 & 1 & - \\
\hline
\end{tabular}

\subsection{A Ten-Shale Gas Companies Example}

In a real case study, the number of wellpads owned by each company increases. Thus, the formulation performance of ten-shale gas companies example which also includes one interruptible water source, one disposal well and one centralized water treatment plant is analysed.

First, to demonstrate the efficiency of the proposed MILP formulation for a large case study, both formulations are solved considering policy 1. The MILP formulation is solved for 10 and 100 grid points using Gurobi and Cplex with 1\% optimality gap.

As might be expected from the solution reported from the previous example, the MINLP solvers do not return any solution (Table 5). The larger is the problem size, greater difficulties has the MINLP solvers to solve the model, gaining the reformulation proposed more importance. Note that in this case Cplex gives a solution faster than Gurobi; nevertheless, Gurobi provides 
a better objective function.

Table 5: Computational performance for the Ten-Shale Companies Example

\begin{tabular}{|c|c|c|c|c|c|c|}
\hline \multirow[t]{3}{*}{ Type } & $\begin{array}{l}\text { \# of } \\
\text { continuous }\end{array}$ & $\begin{array}{c}\# \text { of } \\
\text { s binary }\end{array}$ & $\begin{array}{l}\text { \# of } \\
\text { equations }\end{array}$ & $\begin{array}{ll}\text { Solver } & \text { Gap } \\
\text { s } & (\%)\end{array}$ & $\begin{array}{l}\text { Solution } \\
\text { time }\end{array}$ & $\begin{array}{l}\text { Objective } \\
\text { function }\end{array}$ \\
\hline & variables & variables & & & $(\mathrm{s})$ & \\
\hline & & & & Baron & 3600 & No Solution Returned \\
\hline MINLP & 312,519 & 18,750 & 103,359 & Dicopt & 3600 & No Solution Returned \\
\hline \multirow{2}{*}{$\operatorname{MILP}(q=10)^{*}$} & \multirow{2}{*}{316,299} & \multirow{2}{*}{20,640} & \multirow{2}{*}{111,019} & Cplex 1 & 616 & $11.6203\left(112428^{* *}\right)$ \\
\hline & & & & Gurobi 1 & 1451 & $11.6676\left(117563^{* *}\right)$ \\
\hline \multirow{2}{*}{$\operatorname{MILP}(q=100)^{*}$} & \multirow{2}{*}{317,199} & \multirow{2}{*}{20,640} & \multirow{2}{*}{111,019} & Cplex 1 & 3722 & $11.6769\left(117822^{* *}\right)$ \\
\hline & & & & Gurobi 1 & 5373 & $11.7010\left(120697^{* *}\right)$ \\
\hline
\end{tabular}

Individual company costs obtained under the different policies are shown in Figure 5. Note that significant savings $(\sim 56 \%)$ are obtained when companies work interacting with each other instead of working separately. The mathematical model is also solved without considering the fairness criteria. In this case, the total cost decreases $1 \%$ compared with the solution obtained from policy 1, but the saving ratios are greatly distributed maximizing the Nash product instead of minimizing the total cost.

No significant differences are found comparing policy 1, 2 and 3. Some companies have the same cost with the three policies (as company 6), others (as company 2) a difference of $\$ 508 \mathrm{k}$ can be found depending of the policy selected. Note that the solution obtained using policy 1 provides the higher Nash product and the lowest total cost (Table 6). Therefore, better outcome is obtained with policy 1 given the flexibility of the problem to assign wastewater transportation cost to the issuer or receiver.

Finally, Table 7 displays the cost assignation of each company using policy 1 . In this case study, the optimal solution takes values different from 1 and 0. For example, the transportation cost assignation from company 2 to company 3 is 0.4; therefore, company 2 should pay $40 \%$ of the transportation cost and company 3 the remaining $60 \%$. 


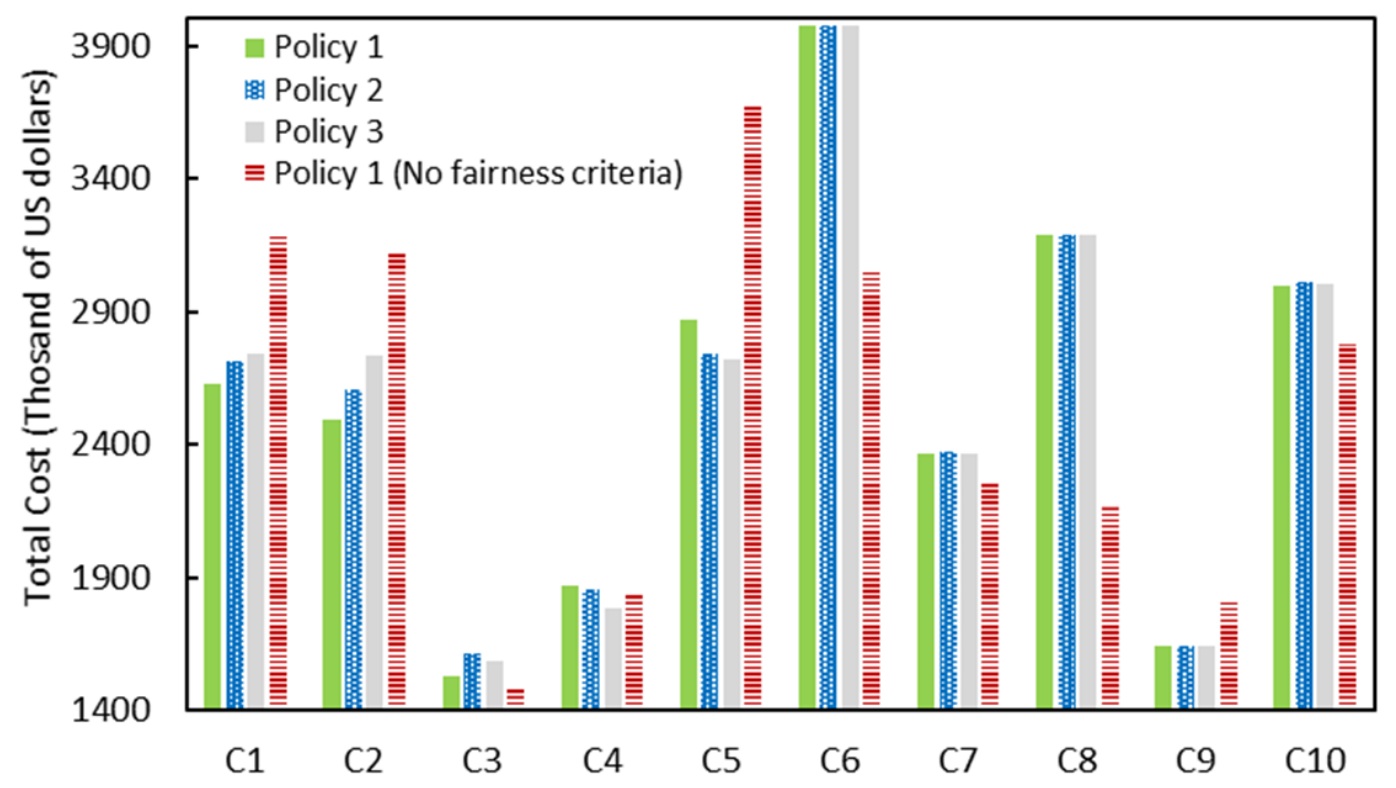

Figure 5: Ten-Shale Companies Example: Optimal fair cost selected by different policies for each company c.

Table 6: Ten-Shale Companies Example: Comparison of Nash product, lineal Nash product and sum of the water management cost for each company obtained with each policy.

\begin{tabular}{cccc}
\hline Policy & Eq.(1) & Eq.(11) & $\sum_{i \in I} t c_{i}$ \\
\hline 1 & 11.70 & 120697 & 25.55 \\
2 & 11.61 & 111196 & 25.72 \\
3 & 11.60 & 109910 & 25.73 \\
\hline
\end{tabular}

\section{Conclusions}

An MINLP model is proposed to address shale gas water planning decisions and provide in turn fair water management cost distribution amongst shale gas companies participants using game theory Nash product. The main interaction between companies is reflected in the wastewater exchange among them to use it as a fracturing fluid. The cost assignation of the water sent from one company to another is analysed under four different policies: the payer can be the issuer or the receiver (policy 1), only the issuer (policy 2), only the receiver (policy 3), or the issuer or receiver but paying the same portion (policy 4). However, it is well-known the high computational efforts required to solve real-world case studies using MINLP formulations. Therefore, a separable programming approach and Glover's linearization 
Table 7: Ten-Shale Companies Example: Cost assignation to transport wastewater from company $i$ to $i$ ' $\left(\gamma_{i i^{\prime}}^{t r}\right)$ via MILP formualtion.

\begin{tabular}{ccccccccccc}
\hline company & i1 & i2 & i3 & i4 & i5 & i6 & i7 & i8 & i9 & i10 \\
\hline i1 & - & 0 & 0 & 0 & 0 & 0.15 & 0 & 0 & 0.25 & 0 \\
i2 & 1 & - & 0.4 & 1 & 1 & 0 & 0.15 & 0 & 0.5 & 0 \\
i3 & 1 & 1 & - & 0.25 & 1 & 0 & 0 & 0 & 1 & 0.2 \\
i4 & 1 & 0.3 & 0 & - & 0.4 & 0 & 0 & 0 & 1 & 0 \\
i5 & 1 & 0.4 & 0 & 0.7 & - & 0 & 0 & 0 & 0 & 0 \\
i6 & 1 & 1 & 1 & 1 & 1 & - & 1 & 1 & 1 & 1 \\
i7 & 1 & 0.9 & 1 & 1 & 0.8 & 0 & - & 0 & 1 & 0 \\
i8 & 1 & 1 & 1 & 1 & 1 & 0 & 1 & - & 1 & 1 \\
i9 & 0.9 & 1 & 0 & 0 & 0.70 & 0 & 0 & 0 & - & 1 \\
i10 & 1 & 1 & 1 & 1 & 1 & 0 & 1 & 0 & 0.95 & - \\
\hline
\end{tabular}

is applied to reformulate the model as an MILP.

Two different case studies are analysed to demonstrate the efficiency of the proposed approach.

First, its efficiency is demonstrated by solving a small numerical example comprising of 30 well belonging to 4 different companies. Then, a bigger size problem comprising 10 companies and 150 wells highlighted the favourable behaviour of the formulation since it is not possible to find an initial point using MINLP formulation.

Fair water management cost distribution is obtained with both examples achieving saving around 35-50 for each company when they are working as a collaborative network. Note the highest Nash product is obtained by applying policy 1; however, not large differences are found when the other policies are applied. Moreover, a comparison of the solution without considering the fairness criteria is done. Although lower total water management cost is obtained, the savings are distributed unfairly for one of the companies. This solution can result in no-interaction of that company with the others, that would cause an increase in total water management cost, decreasing individual company savings.

As a future research direction, uncertainty aspects in water demand and wastewater generation can be considered and included in the optimisation framework. 


\section{Acknowledgments}

The authors would like to thank the financial support received from the UK Engineering and Physical Sciences Research Council (under the project EP/M028240/1).

\section{Appendix A. Mathematical model}

The model presented is an simplified version based on previous work presented by Carrero-Parreño et al. (2018).

\section{Set definition}

$\mathrm{P} \quad=\{\mathrm{p} \mid \mathrm{p}$ is a wellpad $\}$

$\mathrm{W}=\{\mathrm{w} \mid \mathrm{w}$ is a well $\}$

$\mathrm{T}=\{\mathrm{t} \mid \mathrm{t}$ is a time period $\}$

$\mathrm{K}=\{\mathrm{k} \mid \mathrm{k}$ is a CWT $\}$

$\mathrm{F} \quad=\{\mathrm{f} \mid \mathrm{f}$ is a freshwater source $\}$

$\mathrm{D}=\{\mathrm{d} \mid \mathrm{d}$ is a disposal well $\}$

I $\quad=\{\mathrm{i} \mid \mathrm{i}$ is a shale gas company $\}$

$\mathrm{S}=\{\mathrm{s} \mid \mathrm{s}$ is a storage tank $\}$

$\mathrm{Q}=\{\mathrm{q} \mid \mathrm{q}$ interval in $\mathrm{TC}$ linearization $\}$

$R_{p w}=\{$ well $\mathrm{w}$ belongs to wellpad $\mathrm{p}\}$

$G_{i p}=\{$ company i owns wellpad p $\}$

\section{Parameters}

$C_{s} \quad$ Capacity of storage tank s

$C T_{k}^{U P}$ Maximum flow in offsite treatment

$D O_{p k} \quad$ Distance from wellpad p to CWT plant k

$D S_{p f} \quad$ Distance from wellpad p to natural source $\mathrm{f}$

$D D_{p d} \quad$ Distance from wellpad p to disposal place d

$D W_{p p^{\prime}}$ Distance from wellpad p to wellpad p'

$D_{d}^{U P} \quad$ Maximum flow in offsite treatment

$F W_{t p w}$ Flowback water forecast for well w on wellpad $\mathrm{p}$ in time period $\mathrm{t}$

$F S_{t p w}$ Fracturing schedule

$G^{L O} \quad$ Glover's linearization lower bound

$G^{U P} \quad$ Glover's linearization upper bound

$N_{s}^{U P} \quad$ Upper bound of tanks s installed

$N_{s}^{L O} \quad$ Lower bound of tanks s installed

$O T_{p}^{U P}$ Maximum flow in onsite treatment in wellpad $\mathrm{p}$

$O T_{p}^{L O}$ Minimum flow in onsite treatment in wellpad $\mathrm{p}$ 
$T C_{i}^{U P}$ Individual upper total cost for company i

$\hat{T C} C_{i Q}$ Linearised individual total cost for company i at interval $\mathrm{q}$

$W D_{w} \quad$ Water demand to complete well $\mathrm{w}$

$\beta_{p}^{o n} \quad$ Onsite facility fixed cost in wellpad $\mathrm{p}$

$\alpha^{\text {truck }}$ Truking cost

$\alpha_{p}^{o n} \quad$ Desalination cost in wellpad $\mathrm{p}$

$\alpha^{d i s} \quad$ Disposal cost

$\alpha_{f}^{\text {fresh }}$ Fresh water cost for withdrawing water from natural source f

$\alpha^{\text {pre1 }} \quad$ Pretreatment cost aiming to reuse the water

$\alpha^{\text {pre } 2} \quad$ Pretreatment cost aiming to desalinate the water

$\alpha_{k}^{c w t} \quad$ Desalination cost in CWT plant k

$\alpha^{s} \quad$ Storage cost

$\beta^{s} \quad$ Capital cost for mobilize, demobilize and clean out

$\gamma^{\text {pre }} \quad$ Percentage of water recovery in the pretreatment technology

$\gamma^{\text {on }} \quad$ Percentage of water recovery in the onsite desalination treatment

$\gamma_{k}^{\text {off }} \quad$ Percentage of water recovery in the CWT plant $\mathrm{k}$

$\xi \quad$ Extra cost agreement to treat the water in a do not own onsite treatment

\section{Continuous Variables}

$c_{i}^{s} \quad$ Storage cost for company i

$c_{i}^{f} \quad$ Freshwater withdrawal cost for company i

$c_{i}^{c} \quad$ CWT desalination cost for company i

$c_{i}^{d} \quad$ Disposal cost for company i

$c_{i}^{p} \quad$ Pretreatment cost for company i

$c_{i}^{o} \quad$ Onsite treatment cost for company i

$c_{i}^{t} \quad$ Transportation cost for company i

$c_{i}^{t r} \quad$ Inter-company transport cost for company i

$d_{t p w} \quad$ Water demand in well $\mathrm{w}$ on wellpad $\mathrm{p}$ on time period $\mathrm{t}$

$f_{t p}^{i} \quad$ Flowrate of impaired water on wellpad $\mathrm{p}$ on time period $\mathrm{t}$

$f_{t p}^{o} \quad$ Flowrate of wastewater on wellpad $\mathrm{p}$ to onsite pretreatment on time period $\mathrm{t}$

$f_{t p}^{t} \quad$ Flowrate of wastewater on wellpad $\mathrm{p}$ to onsite desalination on time period $\mathrm{t}$

$f_{t p d}^{d} \quad$ Flowrate of wastewater from wellpad $\mathrm{p}$ to disposal well $\mathrm{d}$ on time period $\mathrm{t}$

$f_{t p k}^{c} \quad$ Flowrate of wastewater from wellpad $\mathrm{p}$ to centralized treatment $\mathrm{k}$ on time period $\mathrm{t}$

$f_{t p f}^{s} \quad$ Flowrate of fresh water from natural source $\mathrm{f}$ to wellpad $\mathrm{p}$ on time period $\mathrm{t}$

$g_{t p p^{\prime}}^{i} \quad$ Flowrate of impaired water from wellpad p to wellpad p' on time period t

$g_{t p p^{\prime}}^{t} \quad$ Flowrate of wastewater from wellpad p to treatment placed on wellpad p' on time period t

$l_{t p s} \quad$ Level of water in tank type $\mathrm{s}$ on wellpad $\mathrm{p}$ in time period $\mathrm{t}$

$t c_{i} \quad$ Total cost for company i 
$\alpha_{i} \quad$ Bargaining power for company i

$\gamma_{i i^{\prime}}^{t r} \quad$ Transportation cost assignation from company i to company i'

$\lambda_{i q} \quad$ SOS2 special ordered variable

\section{Binary Variables}

$y_{p}^{o n} \quad$ Indicates where the onsite treatment is installed

$n_{t p s}^{s} \quad$ Number of tanks s on wellpad p on time period $\mathrm{t}$

$n_{t p s}^{i n} \quad$ Number of tanks s installed on wellpad $\mathrm{p}$ on time period $\mathrm{t}$

$n_{p}^{u n} \quad$ Number of tanks s unistalled on wellpad $\mathrm{p}$ on time period $\mathrm{t}$

\section{A.1 Water Demand}

An specific amount of water is required to be available when the well is going to be fractured. The water demand per well on time period $t\left(d_{t p w}\right)$ must be greater than or equal than the total water required per well $\left(W D_{w}\right)$ multiplied by the fracturing schedule $\left(F S_{t p w}\right)$.

$$
d_{t p w} \geq W D_{w} \cdot F S_{t p w} \quad \forall t \in T, p \in P, w \in W
$$

The water required per well can be achieved withdrawing natural water from freshwater tanks $\left(f_{t p}^{s^{\prime}}\right)$, using wastewater from the same wellpad $\left(f_{t p}^{i}\right)$ or provided by another wellpad $\left(g_{t p p^{\prime}}^{i}\right)$. The water provided by another wellpad can belong to the same company or not.

$$
\sum_{w \in R_{p w}} d_{t p w}=f_{t p}^{s^{\prime}}+\sum_{p^{\prime} \in P} g_{t p p^{\prime}}^{i}+f_{t p}^{i} \quad \forall t \in T, p \in P
$$

\section{A.2 Storage Tanks}

Part of the injected water return to the wellhead after a well is drilled. The water is recovered typically from 1 to 5 weeks from which the well begins to be drilled. This water is sent to fracturing tanks placed in the same wellpad. After that, the water has to be managed since it is highly contaminated. It can be sent to an onsite pretreatment $\left(f_{t p}^{o}\right)$, disposal site $\left(f_{t p}^{d}\right)$ or centralized water treatment plant $\left(f_{t p}^{c}\right)$. Hence, the level of the tank in each time period depends on the water recovered in each producing well, the level of the tank in the previous time 
period and the water sent to the pretreatment technology, disposal or centralized treatment.

$$
l_{t p s}=l_{t-1 p s}+\sum_{t^{\prime}=0}^{t^{\prime} \leq t-1} F W_{t-t^{\prime} p w} \cdot F S_{t+\tau_{w}+1 p w}-f_{t p}^{o}-f_{t p}^{d}-f_{t p}^{c} \quad \forall t>1, p \in P, s \in\{f t\}
$$

Water sent to a disposal site and CWT plant are bounded by their upper bounds $D_{d}^{U P}$ and $C T_{k}^{U P}$, respectively.

The level of water in freshwater tanks depends on the inlet water that comes from freshwater sources $\left(f_{t p f}^{s}\right)$, the water accumulated from the previous time period $\left(l_{t-1 p s}\right)$, and the outlet water sent to use it in fracturing operations $\left(f_{t p f}^{s^{\prime}}\right)$.

$$
l_{t p s}=l_{t-1 p s}+\sum_{f \in F} f_{t p w}^{s}-f_{t p}^{s^{\prime}} \quad \forall t>1, p \in P, s \in\{f w\}
$$

Typically, the shale gas industry stores the freshwater and wastewater in portable tanks. Therefore, this model determines the number of tanks needed to be leased in each time period by the following equation.

$$
n_{t p s}=n_{t-1 p s}+n_{t p s}^{i n}-n_{t p s}^{u n} \quad \forall t \in T, p \in P, s \in S
$$

where $n_{t p s}$ refers to the number of tank type $s$ in time period $t, n_{t-1 p s}$ is the number of tanks leased in previous time period, $n_{t p s}^{i n}$ and $n_{t p s}^{u n}$ are the number of tanks installed and uninstalled in time period $t$.

The level of the tank $\left(l_{t p s}\right)$ has to be lower o equal than the number of the tanks installed $\left(n_{t p s}\right)$ multiply by the capacity of one tank $\left(T C_{s}\right)$. We consider that tanks have to handle water that comes from one day. Therefore, the variable $\theta_{t p s}$ is equal to the inlet freshwater or wastewater divided by the number of days into a week.

$$
l_{t p s}+\theta_{t p s} \leq C_{s} \cdot n_{t p s} \quad \forall t \in T, p \in P, s \in S
$$

The number of tanks installed in each time period $t$ has to be lower or equal than the maximum number of tanks $\left(N_{s}^{U P}\right)$.

$$
n_{t p s} \leq N_{s}^{U P} \quad \forall t \in T, p \in P, s \in S
$$




\section{A.3 Onsite treatment}

The water recovery after pretreatment is modelled using a recovery factor $\left(\gamma^{\text {pre }}\right)$.

$$
f_{t p}^{o^{\prime}}=\gamma^{p r e} \cdot f_{t p}^{o} \quad \forall t \in T, p \in P
$$

The outlet pretreated water can be treated in an onsite treatment placed in the same $\left(f_{t p}^{t}\right)$ or another wellpad $\left(g_{t p p^{\prime}}^{t}\right)$, or can be also used as a fracturing fluid also in the same $\left(f_{t p}^{i}\right)$ or another wellpad $\left(g_{t p p^{\prime}}^{i}\right)$.

$$
f_{t p}^{o^{\prime}}=\sum_{p^{\prime} \in P} g_{t p p^{\prime}}^{t}+\sum_{p^{\prime} \in P} g_{t p p^{\prime}}^{i}+f_{t p}^{i}+f_{t p}^{t} \quad \forall t \in T, p \in P
$$

The water recovered in onsite treatment is also modelled using a recovery factor $\left(\gamma^{\text {on }}\right)$. If the onsite treatment is placed in a specific wellpad, it can treat the water that comes from the same wellpad on the neighbouring one.

$$
f_{t p}^{t^{\prime}}=\gamma^{o n} \cdot\left(f_{t p}^{t}+\sum_{p^{\prime} \in P} g_{t p^{\prime} p}^{t}\right) \quad \forall t \in T, p \in P
$$

If onsite treatment is installed in wellpad $p$, the binary variable $\left(y_{p}\right)$ takes the value of 1 and the inlet flow is bounded by the upper $\left(O T_{p}^{U P}\right)$ and lower bound $\left(O T_{p}^{L O}\right)$.

$$
O T_{p}^{L O} \cdot y_{p} \leq f_{t p}^{t}+\sum_{p^{\prime} \in P} g_{t p^{\prime} p}^{t} \geq O T_{p}^{U P} \cdot y_{p} \quad \forall t \in T, p \in P
$$




\section{References}

Caballero, J.A., Labarta, J.A., Quirante, N., Carrero-Parreño, A., \& Grossmann, I.E. (2020). Environmental and Economic Water Management in Shale Gas Extraction. Sustainability, 12, 1686

Carrero-Parreno, A., Onishi, V. C., Salcedo-Díaz, R., Ruiz-Femenia, R., Fraga, E. S., Caballero, J. A., \& Reyes-Labarta, J. A. (2017). Optimal pretreatment system of flowback water from shale gas production. Industrial \& Engineering Chemistry Research, 56(15), 4386-4398.

Carrero-Parreño, A., Reyes-Labarta, J. A., Salcedo-Diaz, R., Ruiz-Femenia, R., Onishi, V. C., Caballero, J. A., \& Grossmann, I. E. (2018). Holistic Planning Model for Sustainable Water Management in the Shale Gas Industry. Industrial \& Engineering Chemistry Research, 57(39), 13131-13143.

Carrero-Parreño, A., Quirante, N., Ruiz-Femenia, R. Reyes-Labarta, J. A., Salcedo-Diaz, R., Grossmann, I. E., \& Caballero, J. A. (2019). Economic and Environmental Strategic Water Management in the Shale Gas Industry: Application of Cooperative Game Theory. AIChE Journal, 65(11), e16725.

Chen, Y., Cheng, X., Li, J., \& He, L. (2020). A multi-level programming for shale gas-water supply chains accounting for tradeoffs between economic and environmental concerns. Computers \& Chemical Engineering, 135, 106761

Drechsel, J. (2010). Cooperative lot sizing games in supply chains (Vol. 644). Springer Science \& Business Media.

Drouven, M. G., \& Grossmann, I. E. (2017). Optimization models for impaired water management in active shale gas development areas. Journal of Petroleum Science and Engineering, 156, 983-995.

Duran, M. A., \& Grossmann, I. E. (1986). An outer-approximation algorithm for a class of mixed-integer nonlinear programs. Mathematical programming, 36(3), 307-339.

EPA. Technical Development Document for the Effluent Limitations Guidelines and Standards for the Oil and Gas Extraction Point Source Category. Washington, DC: U.S. Environmental Protection Agency; 2016.

Gao, J., \& You, F. (2015). Shale gas supply chain design and operations toward better economic and life cycle environmental performance: MINLP model and global optimization algorithm. ACS Sustainable Chemistry \& Engineering, 3(7), 1282-1291.

Gao, J., \& You, F. (2017a). Game theory approach to optimal design of shale gas supply chains with consideration of economics and life cycle greenhouse gas emissions. AIChE Journal, 63(7), 2671-2693. 
Gao, J., \& You, F. (2017b). Design and optimization of shale gas energy systems: Overview, research challenges, and future directions. Computers \& Chemical Engineering, 106, 699-718.

Gao, J., \& You, F. (2019). A stochastic game theoretic framework for decentralized optimization of multi-stakeholder supply chains under uncertainty. Computers \& Chemical Engineering, 122, 31-46.

Gjerdrum, J., Shah, N., \& Papageorgiou, L. G. (2001). Transfer prices for multienterprise supply chain optimization. Industrial \& Engineering Chemistry Research, 40(7), 1650-1660.

Gjerdrum, J., Shah, N., \& Papageorgiou, L. G. (2002). Fair transfer price and inventory holding policies in two-enterprise supply chains. European Journal of Operational Research, 143(3), 582-599.

Guerra, O. J., Calderón, A. J., Papageorgiou, L. G., \& Reklaitis, G. V. (2019). Integrated shale gas supply chain design and water management under uncertainty. AIChE Journal, 65(3), 924-936.

Kılınç, M. R., \& Sahinidis, N. V. (2018). Exploiting integrality in the global optimization of mixed-integer nonlinear programming problems with BARON. Optimization Methods and Software, 33(3), 540-562.

Lira-Barragan, L. F., Ponce-Ortega, J. M., Guillen-Gosalbez, G., \& El-Halwagi, M. M. (2016). Optimal water management under uncertainty for shale gas production. Industrial \& Engineering Chemistry Research, 55(5), 1322-1335.

Lira-Barragán, L. F., Ponce-Ortega, J. M., Serna-González, M., \& El-Halwagi, M. M. (2016). Optimal reuse of flowback wastewater in hydraulic fracturing including seasonal and environmental constraints. AIChE Journal, 62(5), 1634-1645.

Nash, J. F. (1950). Equilibrium Points in n-Person Games. In Proceedings of the National Academy of Sciences of the United States of America (36) 48-49.

Nash, J. F. (1951). Non-Cooperative Games. Annals of Mathematics, 54(2), 286-295.

Oke, D., Mukherjee, R., Sengupta, D., Majozi, T., El-Halwagi, M. (2020). On the optimization of water-energy nexus in shale gas network under price uncertainties. Energy, 203, 117770.

Rahm, B. G., \& Riha, S. J. (2012). Toward strategic management of shale gas development: Regional, collective impacts on water resources. Environmental Science \& Policy, 17, 12-23.

Rosenthal, R. E. GAMS A User's Guide; GAMS Development Corporation: Washington, DC, 2016.

Stadler, H. (2009). A framework for collaborative planning and state-of-the-art. In Supply Chain Planning (pp. 1-26). Springer, Berlin, Heidelberg. 
U.S. Energy Information Administration. Annual Energy Outlook 2019 with Projections to 2050. Washington, DC, USA: U.S. Energy Information Administration (EIA); 2019.

Von Neumann, J., \& Morgenstern, O. (2004). Theory of Games and Economic Behavior (Sixtieth-Anniversary ed.). Princeton University Press, Princeton.

Yaïche, H., Mazumdar, R. R., \& Rosenberg, C. (2000). A game theoretic framework for bandwidth allocation and pricing in broadband networks. IEEE/ACM transactions on networking, 8(5), 667-678.

Yang, L., Grossmann, I. E., \& Manno, J. (2014). Optimization models for shale gas water management. AIChE Journal, 60(10), 3490-3501.

Yang, L., Grossmann, I. E., Mauter, M. S., \& Dilmore, R. M. (2015). Investment optimization model for freshwater acquisition and wastewater handling in shale gas production. AIChE Journal, 61(6), 1770-1782.

Zhang, D., Samsatli, N. J., Hawkes, A. D., Brett, D. J., Shah, N., \& Papageorgiou, L. G. (2013). Fair electricity transfer price and unit capacity selection for microgrids. Energy Economics, 36.

Zhang, D., Alhorr, Y., Elsarrag, E., Marafia, A. H., Lettieri, P., \& Papageorgiou, L. G. (2017). Fair design of CCS infrastructure for power plants in Qatar under carbon trading scheme. International Journal of Greenhouse Gas Control, 56, 43-54. 